\title{
La autoría mediata en la doctrina penal española
}

Indirect Perpetratorship in Spanish Criminal Theory

\section{Orestes Arenas Nero}

Universidad de Panamá. Centro Regional Universitario de San Miguelito, Facultad de Derecho y Ciencias Políticas. Correo: profesororestes@ gmail.com https://orcid.org/0000-0001-5230-3087

Págs.: 12 - 24

Recibido: 8 /8/2020

Aprobado: 18/8/2020

\section{Resumen}

El presente artículo explica cómo se ha entendido la autoría mediata en la doctrina penal española. Para esto, se utilizó la técnica de revisión bibliográfica de distintos autores españoles y textos jurídicos respecto a la temática. Uno de los puntos de discusión más relevantes fue el relativo a las formas de aparición de la autoría mediata, que se dan a través del domino por error, del domino por coacción y del dominio de organización. También se abordó la delimitación entre autoría mediata e instigación, la autoría mediata y los delitos especiales, así como la autoría mediata imprudente. En el mismo se llegó a la conclusión, entre otras, que, el autor mediato es quien comete un delito utilizando a otro como instrumento.

Palabras clave: Derecho penal, autoría mediata, dominio de la voluntad, Derecho penal comparado. 


\begin{abstract}
This paper explained how indirect perpetratorship has been understood in Spanish criminal theory. For this, the bibliographic review technique of different Spanish authors and legal texts on the subject was used. One of the most relevant discussion points was related to the forms of appearance of indirect perpetratorship, which occur through the domain by mistake, the domain by duress and the domain of organization. The delimitation between indirect perpetratorship and abetting, indirect perpetratorship and special crimes, as well as reckless indirect perpetratorship were also addressed. In it, it was concluded, among others, that the indirect perpetratorship is the one who commits a crime using another as an instrument.
\end{abstract}

Keywords: Criminal Law, Indirect Perpetratorship, Domination of the will, Comparative Criminal Law.

\title{
Introducción
}

El Derecho penal protege bienes jurídicos que pueden ser afectados a través de la autoría y la participación delictiva. El presente artículo explica la autoría mediata. Básicamente se admiten 3 formas de autoría, que son: la autoría directa, la coautoría y la autoría mediata. Habrá autoría directa cuando el interviniente realice la conducta típica de manera personal. En cuanto la coautoría, esta consiste en la realización del delito por parte de varios intervinientes. Por su parte, la autoría mediata radica en la realización del delito a través de otra persona, quien es, por lo general, un instrumento que ignora el delito. Es decir, los autores mediatos “《realizan» el hecho, aunque sea «por medio de otro del que se sirven como instrumento».” (Manzaneras, 2016, p. 153).

Las formas de autoría se diferencian de la participación por el concepto de dominio del hecho. Mientras que en las autorías habrá siempre un dominio del hecho, en la participación habrá siempre una subordinación a otra persona, que será la autora del delito. La falta de dominio del hecho lleva a que la persuasión sea una instigación y no una autoría mediata. Esto es así porque "ni el autor mediato realiza una conducta igual a la del inductor o a la del cooperador necesario, ni, mucho menos, a la del cómplice.” (Llinares, 2009, p. 239). 
Antes de la creación del concepto de autoría mediata, existía dificultad para sancionar esta conducta. Por un lado, el concepto restrictivo de autor señala que "quien de manera inmediata cometía el hecho punible y, por consecuencia, la intervención mediata era considerada participación.” (Jiménez, 2017, p. 91). Es decir, un verdadero autor, que controlaba el hecho delictivo era sancionado como partícipe. Pero si se aplicaba el criterio de 'accesoriedad extrema', entonces ese autor mediato, mal considerado partícipe podía quedar impune, "porque cuando el autor era no culpable, aplicada la accesoriedad extrema, también era impune el partícipe” (Jiménez, 2017, p. 91). Estas dificultades han sido superadas gracias a la aceptación del concepto de autoría mediata.

Finalmente, el concepto de autoría mediata es una construcción de la dogmática penal alemana, pero que ha sido ampliamente discutido y aceptado por la doctrina penal española. A tal punto que ha sido incluida en el Derecho positivo español.

\section{Concepto normativo y doctrinario de autoría mediata en España}

En el Reino de España la autoría mediata está consagrada en el Título II 'de las personas criminalmente responsables de los delitos', del Libro I, sobre 'disposiciones generales sobre los delitos, las personas responsables, las penas, medidas de seguridad y demás consecuencias de la infracción penal'. El artículo 28 señala lo siguiente:

"Son autores quienes realizan el hecho por sí solos, conjuntamente o por medio de otro del que se sirven como instrumento.

También serán considerados autores:

a) Los que inducen directamente a otro u otros a ejecutarlo.

b) Los que cooperan a su ejecución con un acto sin el cual no se habría efectuado."

(Lo resaltado no es original) (Ministerio de la Presidencia, Relaciones con las

Cortes y Memoria Democrática, 1995, art. 28)

De lo anterior se desprende que la autoría mediata está expresamente consagrada en el ordenamiento jurídico penal español. Aunque esto no siempre fue así. El Código Penal Español de 1973 no contemplaba todas las formas de autoría, por lo que es el Código Penal de 1995 el que "incorpora la autoría mediata” (Escrihuela, 2016, p. 14). La legislación anterior generaba una serie de problemas doctrinarios y jurisprudenciales, sobre todo entre la aplicación de la autoría mediata y el principio de legalidad. Esto se debía a que se sancionaba a las personas como autores mediatos sin que esta figura existiera en el Código Penal español. Es decir, sanciones sin fundamento legal (o por lo menos debatible), pero con fundamento doctrinario. 
De este artículo 28 se deriva que la autoría mediata es "aquélla en la que el autor no realiza directa y personalmente el delito, sino sirviéndose de otra persona, generalmente no responsable, que es quien lo realiza." (Muñoz \& García, 2010, p. 435). Esto quiere decir que el verdadero autor no realiza la acción típica de manera personal, si no que, valiéndose de otra persona (el instrumento) comete el delito. Por ejemplo, “el hipnotizador que obliga al hipnotizado a cometer un delito, o el que fuerza a otro con violencia o con engaño a suscribir un documento falso, realizan directamente el delito y dominan su acción.” (Muñoz \& García, 2010, p. 435). En estos ejemplos, el hipnotizador y el que ejerce fuerza o engaña a otro, sería el autor mediato. En síntesis, el autor mediato es "quien realiza el hecho utilizando a otro como instrumento" (Mir Puig, 2006, p. 382).

La razón para sancionar al hombre de atrás, es que él "es el verdadero autor, quien realiza el hecho como propio" (Demetrio y Rodríguez, 2010, p. 385). No es el instrumento quien tiene el ánimo de autor, pero, lo más importante, no tiene un control sobre la realización del delito, sino que es una herramienta de otra persona (el autor mediato).

Para realizar el delito, el autor mediato "se vale como instrumento de un inimputable o de una persona a la que se induce a error sobre la ilegalidad de la conducta" (Escrihuela, 2016, p. 252). Por lo que el inimputable no es el autor, si no, el que utiliza al inimputable es el autor. Tampoco sería penalmente responsable el instrumento si es inducido a un error, o si es forzado a cometer el hecho. Ahora bien, si el instrumento es utilizado como una masa, no habría autoría mediata, sino una autoría directa. Esto se debe a que el instrumento no realizaría ninguna acción. Por ejemplo, A empuja a B contra el vehículo de su enemigo C y le quiebra los vidrios. En este caso, A es autor directamente del delito de daños, y no un autor mediato. Tampoco se admite el uso de animales o cosas como formas de autoría mediata. En estos casos siempre habría una autoría. En este sentido se ha sostenido que "cuando la conducta del instrumento carece de los presupuestos necesarios para la concurrencia de acción, puede ser asimilada a un instrumento mecánico y, por tanto, el hombre de atrás será autor directo” (Del Castillo, 2007, p. 177).

Cuando el instrumento es utilizado como masa mecánica "no se puede hablar de participación, porque la persona, instrumento de la que se sirve el autor mediato, ni 
siquiera actúa típicamente. (Muñoz \& García, 2010, p. 435). En estos casos no hay autoría mediata, ya que el que empuja a otro pasa a ser autor directo, en virtud que el instrumento no actúa. Por ejemplo, también sería autor directo quien usa un perro para atacar a otra persona, ya que es la persona la que controla al perro. Además, los animales no realizan conductas reprochables penalmente. La autoría mediata exige que el instrumento actúe de manera consciente, aunque desconozca que está realizando un delito. En este sentido Mir Puig ha sostenido que si el instrumento "no realiza un comportamiento humano no se halla justificado acudir a la autoría mediata" (Mir Puig, 2006, p. 383). Por lo que se debe resolver como autoría directa y no como autoría mediata.

Por otro lado, una característica importante de la autoría mediata es que "se exige una relación de subordinación" (Demetrio y Rodríguez, 2010, p. 385). Es decir, el instrumento debe estar supeditado a la voluntad del hombre de atrás. Esto se debe a que “el instrumento actúa sin libertad o sin conocimiento, esto es, víctima de un engaño (error), bajo coacción o padeciendo una situación de inculpabilidad." (Demetrio y Rodríguez, 2010, p. 385). Si el instrumento actuara voluntariamente, entonces no sería instrumento, sino un autor propiamente. Por lo que no habría un instrumento, sino un autor director; y el hombre de atrás no sería un autor mediato, sino un instigador.

Por su parte, algunos autores señalan que "el inciso tercero del párrafo primero del art. 28 cuando incluye entre los auténticos autores a quienes realizan el hecho por medio de otro del que se sirven como instrumento.” (Muñoz \& García, 2010, p. 435). Es decir, señalan que la autoría mediata se puede fundamentar en la frase "Los que inducen directamente a otro u otros a ejecutarlo" (Ministerio de la Presidencia, Relaciones con las Cortes y Memoria Democrática, 1995, art. 28). De esta manera se confunde la autoría mediata, que implica un dominio del hecho, con la instigación, que implica una participación en un hecho delictivo dominado por otro. Aunque ambas formas de inducción son punibles, no es menos cierto que en la autoría mediata el interviniente que realiza la acción directamente no es punible, mientras que en la instigación dicho interviniente sí lo es. Por ejemplo, A convence a B para que lleve drogas de un país a otro (inducción). En este supuesto, A es instigador mientras que B es autor. Diferente sería el caso si A le introduce drogas a B en su equipaje, y B la transporta sin conocimiento. En este otro supuesto, A es autor mediato, mientras que B es un instrumento no punible. Esto se debe a que, en el primer supuesto, B sabría a quien 
GUACAMAYA

darle la droga (tendría dominio del hecho), mientras que en el segundo supuesto A deberá controlarlo todo, acaparando para sí el dominio del hecho.

\section{Delimitación entre autoría mediata e instigación}

Los doctrinarios penales en España siguieron por muchos años distintas teorías para delimitar la autoría de la participación, pero la teoría del dominio del hecho es actualmente "asumida por un sector importante de la doctrina española, siendo utilizada no uniformemente, pero cada vez más asiduamente, por la jurisprudencia del Tribunal Supremo español" (Benítez Ortúzar, 2007, p. 47). De esta manera se reafirma el uso de la teoría del dominio del hecho como principal concepto teórico que delimita la autoría de la participación delictiva. Específicamente, la autoría mediata de la instigación.

Según la teoría del dominio del hecho, sería autor "quien sin intervenir de propia mano es portador del dominio del hecho y se vale de otra persona a quien utiliza como instrumento.” (Jiménez, 2017, p. 91). Es decir, el autor mediato controla la realización del hecho delictivo. Por ejemplo, A cambia la medicina de su padre B por un veneno. La enfermera al inyectar el veneno, creyendo que es la medicina, ocasiona la muerte de B. En este supuesto, A no inyectó a su padre con el veneno, pero fue el único que controló la realización del delito, en el sentido que decidió si el homicidio ocurriría o no, así como también decidió cómo ocurriría. A pudo interrumpir en cualquier momento el homicidio. Todos estos elementos demuestran que fue él quien controló el hecho, aunque no haya sido la persona que puso la inyección.

El dominio del hecho se fundamenta en "el dominio de la voluntad del que actúa por parte del autor mediato" (Muñoz \& García, 2010, p. 435). Es el autor mediato quien hace prevalecer su voluntad sobre el instrumento. El instrumento puede desconocer que su conducta es típica (desconoce que comete un delito), o puede cometer el delito bajo coacción (sabe que es un delito, pero no tiene otra opción, por lo que no se le puede exigir otra conducta). Algunos doctrinarios sostienen que la autoría mediata "supone normalmente la ausencia de acción en el instrumento humano del que se sirve.” (Muñoz \& García, 2010, p. 435). Sin embargo, si el instrumento no realiza ninguna acción, no habría autoría mediata, si no, autoría directa. Para que haya autoría mediata, el instrumento debe carecer de conocimiento o de voluntad frente al delito. Es decir, no 
debe saber que su conducta es delictiva; o, aun sabiendo que es delito, no quiere realizarlo, pero es compelido a ello.

Además, la autoría mediata "no compagina con la teoría subjetiva ni con la formalobjetiva de autor, pues no es el animus auctoris ni la ejecución de propia mano del hecho punible lo que da la categoría de autor.” (Jiménez, 2017, p. 92). El ánimo de autor solo sirve para explicar la autoría personal o directa, pero presenta dificultades para demostrar la autoría mediata, ya que el que actúa es un interviniente distinto al autor mediato. Mientras que la teoría formal rechaza que sea considerado autor alguien que no realice directamente el hecho delictivo. Actualmente, solo se puede explicar la autoría mediata bajo los postulados de la teoría del dominio del hecho.

En este sentido, solo la teoría del dominio del hecho permite diferenciar al autor mediato del instigador. En la instigación, es el autor directo que domina la realización del hecho, mientras que el instigador hace nacer la voluntad criminosa en el primero. Ambos son reprochables. Mientras que, en la autoría mediata, el autor mediato es "el único que domina el hecho, ya que el instrumento suele actuar de modo penalmente irreprochable" (Blanco, 2005, p. 475). Entonces, el instrumento es impune. Aunque en los casos de dominio de la organización, el autor mediato es penalmente responsable, al igual que el autor directo. Por ejemplo, el general A le ordena al soldado B (a través de toda la cadena de mando) disparar contra la población civil. En este caso, el general A es autor mediato, mientras que el soldado B es autor directo. Ambos son penalmente sancionables.

Por otro lado, “el hombre de atrás, pues puede ser considerado autor mediato por valerse del instrumento inimputable, o bien puede ser considerado inductor (partícipe) de ese mismo hecho cometido por el inimputable." (Demetrio y Rodríguez, 2010, p. 386). La diferencia estriba en quién posee el dominio del hecho. Si el instrumento posee el dominio del hecho, entonces habrá instigación. Pero, si el hombre de atrás posee el dominio del hecho, entonces habrá autoría mediata. Es decir, "si el presunto instrumento no se encuentra en los supuestos de falta de libertad o falta de conocimiento, recaerá en él directamente la condición de autor del hecho delictivo que está realizando.” (Demetrio y Rodríguez, 2010, p. 386). Esto se debe a que tiene conocimiento de la ilicitud de su acción, y, además, quiere realizarla. 


\section{Formas de aparición de la autoría mediata}

Si bien es cierto, la autoría mediata es una sola, también es cierto que esta se puede dar de tres formas: la autoría mediata a través del domino por error, del domino por coacción y del dominio de organización. Primero está el domino por error, según el cual el autor mediato domina "la voluntad del ejecutor a través del engaño sobre las circunstancias reales del hecho que éste realizaba, o al darle al suceso donde aquél intervenía, un sentido o significado distintos del que realmente le correspondía." (Jiménez, 2017, p. 92). Por ejemplo, A le da un café a B para que se lo de a C. Lo que B no sabía es que el café contenía un veneno que le ocasionó la muerte a C. Si bien B es el que le da a beber el veneno a $\mathrm{C}$, en realidad A fue quien tenía la intención y el conocimiento de la realización del hecho. Es decir, A dominaba por error de B, el homicidio en contra de $\mathrm{C}$.

Esta modalidad se puede dar cuando "el instrumento no actúa típicamente porque falta en él [...] un elemento subjetivo que exija el tipo delictivo.” (Muñoz \& García, 2010, p. 435). Es decir, cuando el instrumento no cumple con elementos subjetivos de la tipicidad, como lo es el dolo. Por ejemplo, "es autor mediato de hurto el granjero que ordena a su empleado que meta en la partida de ganado algunas cabezas del ganado del vecino, sin saber el empleado que es ganado ajeno.” (Muñoz \& García, 2010, p. 435). En este caso, el empleado no tiene la intención de apoderarse él o que se apodere su jefe del ganado de manera ilegal. Él desconoce que está cometiendo un delito, ya que es su jefe el que sabe que el ganado no le pertenece, y, aun así, actúa sobre este como dueño (animus lucrandi).

También se da "cuando alguien aprovecha o provoca el error de tipo o de prohibición del instrumento.” (Muñoz \& García, 2010, p. 436). El error de tipo es cuando el instrumento ignora que está cometiendo un hecho delictivo. Al contrario, piensa que su actuación no es típica. El único que sabe que es típica es el autor mediato. Por ejemplo, "el cazador que grita a otro que dispare a la pieza, sabiendo que es una persona" (Muñoz \& García, 2010, p. 436). De lo anterior se desprende que el instrumento piensa que está disparando contra un animal cuya caza es permitida, por lo que cree que no está cometiendo ningún delito. Por su parte, el otro cazador sabe que es una persona y quiere 
que le disparen, razón por la cual incita a disparar, por lo que es autor mediato del hecho.

Otro supuesto es el error de prohibición en el que el instrumento piensa que está actuando lícitamente, cuando en realidad está cometiendo un delito. Este es el caso de “quien provoca en un timorato un estado de legítima defensa putativa, que le hace disparar contra una persona. (Muñoz \& García, 2010, p. 436). Por ejemplo, A es seguridad en un banco junto a B. A ve que su enemigo C llega al banco, por lo que hace un disparo al aire y corre hasta donde $\mathrm{B}$, y le dice que $\mathrm{C}$ está asaltando el banco. B sale y dispara contra C causándole la muerte. Si bien es cierto B quería disparar contra C y neutralizarlo, así fuese ocasionándole la muerte, también es cierto que B pensaba que estaba amparado en una causa de justificación. Lo que ignoraba B es que no había ninguna amenaza contra él ni el personal del banco.

Segundo está el domino por coacción, según el cual "el hombre de atrás conducía la voluntad del ejecutor empleando la amenaza o intimidación de un mal inminente y grave que estaba en sus facultades realizar.” (Jiménez, 2017, p. 92). En este caso el instrumento no es reprochable porque no tiene capacidad de autodeterminarse. Es decir, él comprende que el hecho está mal, pero no puede actuar de acuerdo a esa comprensión, debido a una coacción que sufre por el hombre de atrás, quien es en realidad el autor mediato. Por ejemplo, A secuestra a la suegra del perito privado B y amenaza con matarla, si B no rinde un peritaje que favorezca a A en un juicio penal. Entonces B da un dictamen falso. En este caso, B no sería autor ${ }^{1}$ del delito de 'falso testimonio', si no que A sería autor del delito de amenaza para obtener un falso testimonio. Esto se debe a que A dominó por coacción la realización del delito, en el cual B solamente fue un instrumento. Es importante destacar que la amenaza debe ser grave, por lo que se deben rechazar intimidaciones leves. Por ejemplo, si en vez de amenazar de muerte a su suegra, A hubiera amenazado a B de quitarle su amistad. En este supuesto hay instigación por parte de A, y autoría directa por parte de B.

Esta modalidad de autoría mediata también se da "cuando el instrumento actúa justificadamente" (Muñoz \& García, 2010, p. 435). Es decir, cuando el autor mediato coloca a una persona en una situación de peligro, que esta solamente pueda defenderse,

\footnotetext{
${ }^{1}$ Si no lo denuncia a tiempo, podría ser perseguido penalmente por omitir informar a las autoridades de un delito (secuestro).
} 
o defender a un tercero, a través de una agresión justificada. Por ejemplo, "quien azuza a un perro o induce a un enfermo mental a atacar a otra persona, responde de daños o de homicidio en autoría mediata si la persona atacada mata al perro o al enfermo mental (obsérvese que el instrumento es quien se defiende, no el perro o el enfermo mental)." (Muñoz \& García, 2010, p. 435). De lo anterior se desprende que es la persona de atrás la que produjo el hecho delictivo. Si el autor mediato no incita al perro, entonces, el perro no atacaría al instrumento, y este no se tendría que defender legítimamente matando al perro, y, por ende, no se produciría un delito contra los animales domésticos.

Esta tesis puede tener inconvenientes, porque el dominio del hecho implica un control sobre el delito, sin embargo, quien azuza a un perro a atacar a otra persona no sabe cómo va a responder el agredido. Mucho menos se puede saber si un enfermo mental va a agredir a otra persona si es motivada a ello (salvo que sea el psiquiatra del enfermo mental). Por ejemplo, A le dice al enfermo mental B que $\mathrm{C}$ es la reencarnación Caín y que hay que matarlo. A no sabe si B va a tratar de matar a $\mathrm{C}$, y mucho menos si $\mathrm{C}$ va a defenderse usando fuerza letal contra B.

Esto podría ser resuelto a través de una extensión del concepto de dolo eventual, y señalar que A es responsable como autor de todo lo que podía prever que pasara. Y como el instrumento es el que ejecutó la conducta descrita en el tipo, entonces A es autor mediato. Aunque también podría discutirse si A es autor de un delito culposo de homicidio, en virtud que no controla el hecho y que no era posible prever que $\mathrm{C}$ mataría a B.

Tercero está la autoría mediata por dominio de la voluntad en aparatos de poder organizados, la cual se basa en el "dominio de organización” (Jiménez, 2017, p. 95). Esta forma de autoría mediata es más compleja, ya que requiere que se cumplan una serie de elementos para sancionar a una persona como autor mediato. Por ejemplo, un general ordena, a través de toda la cadena de mando, cometer un genocidio. En este caso, los soldados son autores directos del genocidio, pero el general también es autor mediato de este delito.

\section{Autoría mediata y los delitos especiales}


Los delitos especiales son aquellos que exigen una cualidad específica en el autor. Por ejemplo, para cometer un peculado, hay que ser servidor público. Si alguien no es servidor público y se apodera de un bien del Estado, entonces no cometería peculado, si no hurto. Al ser la autoría mediata una forma de autoría, entonces, un requisito para sancionar a alguien como autor es que el interviniente "ha de reunir las mismas cualidades exigibles para todo autor propiamente dicho" (Manzaneras, 2016, p. 154). La primera consecuencia es que no se exige que el instrumento tenga las cualidades del autor. Por ejemplo, "El funcionario hace destruir a su secretaria particular unos papeles confiados a aquél por razones de su cargo" (Mir Puig, 2006, p. 382). Para sancionar al funcionario, no es necesario que su secretaria sea una servidora pública, pues basta que él lo sea para sancionarlo como autor del delito de 'infidelidad en la custodia de documentos’ (legislación de España, no de Panamá).

No importa que el instrumento no tenga las características especiales del sujeto activo. Por ejemplo, en el delito de 'infidelidad en la custodia de documentos', no importa que el instrumento no sea servidor público. En este supuesto, al ser el hombre de atrás funcionario, entonces puede ser considerado autor mediato, ya que el responsable del delito es él, y no el instrumento.

Según esta tesis, en los delitos especiales (con un sujeto activo determinado), como lo es el peculado, el autor mediato debe ostentar la cualidad de servidor público. De no serlo, entonces no sería autor mediato de peculado, si no, autor mediato de otro delito. Esto se debe a que "es posible que la actuación del realizador material no pueda realizar el tipo pero sí permitir que con ella la persona de atrás lesione el bien jurídico protegido.” (Mir Puig, 2006, p. 382).

Pero ¿qué sucede si el hombre de atrás no tiene la cualidad de servidor público, pero el instrumento sí? Por ejemplo, A engaña al servidor público B y este le lleva una computadora del Estado para que le actualice unos programas, pero en realidad A termina apropiándose de ella. B no realiza el delito, ya que es instrumento de A. Pero A no es servidor público, por lo que cometería sería un hurto y no un peculado. Esto se debe a que no puede ser autor de peculado alguien que no sea un servidor público. Sin embargo, hay que buscar en la legislación penal para determinar si su conducta se subsume en otro delito. 


\section{Autoría mediata imprudente}

La autoría mediata imprudente debe ser rechazada, sin embargo, un sector de la doctrina la permite. Por ejemplo:

"es autor mediato quien, con el fin de abusar sexualmente de una mujer, se esconde en la parte trasera del coche por aquella conducido, y estando el vehículo en marcha, la coge súbita e inesperadamente por la espalda, lo que provoca que la conductora, aterrorizada, suelte instintivamente el volante volviéndose hacia atrás, a consecuencia de lo cual el vehículo colisiona contra otros dos" (Del Castillo, 2007, p. 177)

Frente a este cuadro fáctico, la solución más factible sería condenar al agresor sexual como autor doloso del delito de daños, ya que, al atacar a un conductor, existe la probabilidad previsible que se ocasione un accidente, por lo que quien ejecuta dicha acción puede tener un dolo eventual sobre el resultado. Es decir, cualquier persona puede prever que, al atacar a un conductor de un automóvil, existe una gran probabilidad de que la persona atacada deje de prestar atención al volante y se enfoque en defenderse de la agresión, por lo que se perderá el control del vehículo. Por lo que no importa si no era su intención final, lo que importa es que una conducta dolosa sea el origen del resultado, y que haya sido previsible ese resultado.

\section{Conclusiones}

$\mathrm{El}$ autor mediato es quien comete un delito utilizando a otro como instrumento. El instrumento actúa bajo violencia o engaño por parte del autor mediato.

El Código Penal de 1995 es el que incorpora la autoría mediata en el ordenamiento jurídico español, ya que previamente esta figura no existía en la norma.

Cuando el instrumento es utilizado como masa mecánica no hay autoría mediata, sino autoría directa. La autoría mediata exige que el instrumento actúe de manera consciente, aunque desconozca que está cometiendo un delito.

La teoría del dominio del hecho es el concepto teórico más adecuado para diferenciar a la autoría mediata de la participación delictiva. 
Existen tres formas de aparición de la autoría mediata: a través del domino por error, del domino por coacción y del dominio de organización.

Al ser la autoría mediata una forma de autoría, entonces se requiere que el interviniente reúna las cualidades exigibles para todo autor propiamente dicho.

\section{Referencias Bibliográficas}

Benítez Ortúzar, I. (2007). La participación en el delito imprudente en el Código Penal español de 1995. Madrid, España: Editorial Dykinson, S.L.

Blanco, C. (2005). Tratado de Derecho penal español. Volumen 2. La estructura del delito. Barcelona: J. M. Bosch Editor.

Demetrio, E. \& Rodríguez C. (2010). Curso de Derecho penal Parte General. $2^{a}$ edición. Barcelona, España: Ediciones Experiencia, S.L.

Del Castillo, E. (2007). La imprudencia: autoría y participación. Madrid, España: Editorial Dykinson, S.L.

Escrihuela, J. (2016). Todo penal. Madrid, España: Wolters Kluwer España, S.A.

Jiménez Martínez, C. (2017). Dominio del hecho y autoría mediata en aparatos organizados de poder. Madrid, España: Dykinson S.L.

Manzaneras, J. (2016). Comentarios al Código Penal. Madrid, España. Wolters Kluwer.

Ministerio de la Presidencia, Relaciones con las Cortes y Memoria Democrática (1995). Legislación consolidada. España. Recuperado de https://www.boe.es/buscar/pdf/1995/BOE-A-1995-25444-consolidado.pdf

Mir Puig, S. (2006). Derecho penal Parte General. $8^{a}$ edición. Barcelona, España: Editorial Reppertor.

Miró Llinares, F. (2009). Conocimiento e imputación en la participación delictiva. Aproximación a una teoría de la intervención como partícipe en el delito. Barcelona, España: Atelier Penal.

Muñoz, F. \& García, M. (2010). Derecho Penal Parte General. Valencia, España: Tirant lo Blanch. 